\title{
Chinese and international visitor perceptions of interpretation at Beijing built heritage sites
}

\begin{abstract}
Research exploring visitor perceptions of heritage sites indicates that a site may hold different meanings for visitors depending on their cultural backgrounds. Little research has, however, identified visitor cultural preferences, and so informed the development, delivery and management of on-site heritage interpretive experiences. This paper addresses this need by identifying cultural differences and similarities between Chinese and international visitors in relation to their interpretive motives, preferences and perceptions. Questionnaires were completed by 277 domestic Chinese visitors and 94 international visitors at five key Beijing built heritage sites. Differences between Chinese and international visitors' conceptions of heritage; ratings of importance of facilities, services and interpretive content; and perceptions of the visitor experience are identified. Amongst many findings, Chinese respondents were more likely than international respondents to state that heritage sites should be an important part of the country's national heritage, convey the country's power, and be famous. They sought built heritage sites visited by someone famous and that feature in well-known Chinese paintings and poetry. International visitors were more likely than Chinese to state that heritage sites should have authentically old buildings, and be relevant to contemporary life. Implications for interpretive and management practice at Chinese heritage sites are discussed.
\end{abstract}

\section{Introduction}

Heritage tourism encompasses the historic, natural and cultural values of a destination and occurs in a wide variety of landscapes and settings. It is an important and growing sector of the tourism industry, and has received considerable attention particularly in relation to both management and marketing issues (Poria, Butler and Airey, 2003). Definitions of 'heritage tourism' are many and varied, and over the years have incorporated a number of different elements including cultural heritage, urban or built heritage, industrial heritage, maritime heritage, rural heritage, culinary heritage, ethnic heritage and human heritage (Ung and Vong, 2010). Typically, however, heritage tourism includes a focus on architecture and the built environment (e.g., churches, castles); sites of archaeological or cultural/historic significance; museums and cultural centres; and/or places that are renowned for their natural or environmental beauty (Bonn, Joseph-Mathews, Dai, Hayes and Cave, 2007).

While early research work on heritage tourism focused on the conservation and preservation of antiquities and historic spaces, more recent studies have changed from a product-focussed concern to one that is visitor focussed, i.e., concerned with exploring the interaction between the tourist and the heritage resource. Discussions have centred on the issue of sustainability and how sites can develop practices, principles and management strategies that contribute to 
the long-term viability of heritage attractions and destinations; not only economically but also socially and culturally (Weiler and Kim, 2011). To this end, the heritage tourism framework proposed by Timothy and Boyd (2003) highlights the importance of considering the authenticity of heritage artefacts; the role of interpretation in explaining and promoting the site's significance; the degree of access and how this is likely to impact on host communities; and ways of ensuring that heritage attractions are open to all, both now and in the future. The framework also stresses that heritage tourism attractions can only be sustainable if managers adopt a long-term focus.

The current study centres on one aspect of Timothy and Boyd's (2003) framework interpretation. Interpretation refers to modes of visitor communication such as signs, exhibits, brochures, talks and costumed performances that are specifically designed to help visitors understand, appreciate and engage with heritage sites. Studies in a wide range of settings indicate that well-designed interpretation has the potential to enhance the visitor experience (Van Dijk and Weiler, 2009); encourage visitors to care about the site and its resources (Huang and Weiler, 2010); minimise the negative impacts of tourism (Moscardo, 1998; Weiler and Kim, 2011); prompt visitors to donate time or money to conservation initiatives (Powell and Ham, 2008); change visitors' knowledge, attitudes and facilitate the adoption of environmentally sustainable behaviour (Ballantyne, Packer and Falk, 2011; Munro, Morrison-Saunders and Hughes, 2008); and enhance the economic viability of the site, and thus help pay for conservation measures (Io, 2013; Wong, 2013). Because interpretation contributes to visitors' understanding of the cultural, environmental and social significance of heritage sites, researchers also claim it plays a pivotal role in creating both demand and support for the conservation of historic places (Huang and Weiler, 2010; Io, 2013).

\section{Cultural differences and visitors' responses to heritage interpretation}

Interpretation in a heritage tourism context refers to the provision of visitor information and experiences in a way that communicates the significance of the heritage resource or site being viewed. Studies assessing visitors' perceptions of heritage interpretation predominantly focus on visitors' acquisition of objective knowledge (what visitors have learnt) or subjective knowledge (what visitors think they have learnt). There has been some exploration of changes in visitors' personal attitudes and behaviour (Ballantyne, 2011); the impact of prior knowledge on the acquisition of new knowledge (Falk and Dierking, 2000); the impact of emotion on the visitor interpretive experience (Ballantyne, Packer and Bond, 2012; Kang, Scott, Lee and Ballantyne, 2012; Poria et al., 2003); and the influence of culture on the visitor experience (Ballantyne and Packer, 2011; Cui, Xu and Wall, 2012; Xu, Cui, Ballantyne and Packer, 2013).

The results of these studies support Tilden's (1977) argument that the key to designing powerful heritage interpretive experiences lies in knowing one's target audience. Accordingly, visitor experience designers and heritage site managers need a detailed understanding of their visitors - their motives for visiting, previous experiences, prior knowledge, preferences for interpretation and cultural backgrounds (Ballantyne, 1998; 
Ballantyne, Packer and Sutherland, 2011; Falk and Dierking, 2000; Moscardo, Ballantyne and Hughes, 2007; Xu et al., 2013). Such knowledge is essential in order to effectively engage visitors in the interpretive experience and facilitate the co-creation of new visitor learning. In this process, an individual's culture (shared experiences, beliefs, customs and values) plays an important role in mediating and colouring their interaction with, and meaning-making in relation to, interpretive material and experiences.

Poria et al. (2003) recommend careful consideration be given to how visitors from different cultural backgrounds perceive and experience heritage settings and Poria, Reichel and Biran (2005) note that the way heritage sites are experienced depends on the interaction between site attributes and visitors' cultural background. Timothy and Boyd (2003) caution that interpreters need to be sensitive to different cross-cultural perspectives, explaining that some cultures regard Eurocentric approaches to interpretation (panels, guided tours) as inappropriate for sacred or special places. Likewise, Moscardo (2007) emphasises that the principles of interpretation are Western in origin and may therefore not be appropriate for other cultural groups. She suggests that different cultural groups are likely to react differently to interpretive text and illustrations, and may have clear preferences for material presented as either brochures, signs, presentations, models or guided tours (Moscardo, 2003). She also notes that different cultural groups may have different motives, expectations and perceptions of interpretive experiences. Austin (2002) found this to be the case - when investigating the impact of cultural differences on visitor perceptions of interpretation at a heritage site, he discovered that interpretive preferences, perceptions and satisfaction differed depending on whether visitors were African-American or Caucasian. This suggests that a site may hold different meanings for visitors depending on their cultural backgrounds (Ballantyne, 2003). Importantly, as Moscardo (2003) and Xu et al (2013) note, differences in cultural expectations, preferences and perceptions are likely to substantially impact on visitor satisfaction and engagement with interpretive experiences at heritage sites.

Surprisingly, a literature search indicates that little work has been undertaken to identify visitor cultural preferences to inform the development, delivery and management of on-site heritage interpretive experiences, even at sites attracting large multi-cultural groups (AlMuhrzi, 2012). This is particularly the case in relation to Chinese heritage sites, many of which are attracting increasing numbers of both international and domestic tourists. Studies in China show that seeking enlightenment and cultural meaning is evident in patterns of Chinese domestic tourism. Sites and landscapes that have inspired famous art and literary works are now being visited by millions of Chinese every year. It has also been observed that many Chinese visitors travel set routes established over the centuries, 'ticking off' important places in a predetermined sequence and recalling famous literary pieces as they proceed ( $\mathrm{Li}$ and Sofield, 2009). In this manner, Chinese tourists 'walk in the footsteps of the famous' and connect on many levels with works of art and their creators. What is not so clear is whether the information and tourist experiences offered at heritage sites are meeting the needs of these domestic tourists, or indeed, whether international tourists have similar motivations and interpretive needs. Research into Chinese and international visitors' interpretation 
preferences is thus important given the improved access to China as a tourist destination, and the rapid growth of both domestic and outbound Chinese tourism.

According to the WTO, by 2020 China will be the world's largest destination and the fourth largest source of outbound tourists (Hongying and Hui, 2009) with the latter predicted to rise to 115 million by 2020 (Wah, 2009). The rise of Chinese domestic tourism means that the relationship between host and visitor is changing - no longer can it be assumed that Chinese heritage sites are being visited by mainly international visitors and thus interpreters need to explore and develop global approaches to designing meaningful tourist experiences (Winter, 2009). Many of our concepts and views of heritage, traditions and authenticity, as well as theories, processes and practice of interpreting these, evolve from Western discourse (Cui et al, 2012; Weiler, et al, 2007; Winter, 2009; Xu et al, 2013). Li and Sofield (2006) describe the potential problems this creates by describing interpretive signs at Huangshan that have been designed to conform to UNESCO World Heritage Site requirements. The authors describe the resultant signs as an amalgamation of "Western scientific technicalities and Chinese cultural values" (p.257) and report that because comprehension requires Chinese 'common knowledge', non-Chinese visitors are unlikely to make sense of the text. Further questioning of Chinese visitors revealed that almost none stopped to read the panels, mainly because they contained scientific information they were not interested in or cultural information that they already knew. It is time, therefore, to investigate whether theories and interpretive practices are universally applicable - do Western-based 'best practice' principles of heritage interpretation apply and appeal to Chinese visitors to Chinese heritage sites? Do non-Chinese visitors have similar needs and preferences? If Chinese and Western visitors perceive the interface between past and present differently, how should we interpret the past in a way that appeals to both?

\section{The Chinese visitor and heritage interpretation}

To appreciate why the interpretive needs of Chinese visitors may differ from those of visitors from other cultures it is necessary to briefly consider the history of heritage tourism in China and how this impacts on Chinese visitors' motives, preferences and perceptions. Domestic tourism in China dates back to the Shang dynasty (circa 1600 - 1050BC), when emperors and their courts began the tradition of visiting heritage sites to pay homage to gods and goddesses (Sofield and Li, 1998). This tradition was based on the belief that sites such as mountains, rivers, lakes and other natural formations were the home of ancestral gods and spirits. Temples and holy sites related to the Buddhist religion were also considered important pilgrimage sites, attracting many visitors.

In the $5^{\text {th }}$ and $6^{\text {th }}$ century BC, Confucianism emerged as an important influence on Chinese culture and tradition. Confucianism values the veneration of landscapes through art, calligraphy and poetry, therefore landscapes are inextricably linked to images, messages and ideas created by emperors, courtiers, artists, poets, philosophers and other important individuals stretching back thousands of years. These artistic and literary works have inspired and influenced generations of Chinese to this day. They are instantly recognised by Chinese around the world, and are considered part of Chinese 'common knowledge' (Sofield 
and $\mathrm{Li}, 1998$ ). Thus, Chinese paintings and poems are not so much portraits of landscapes but rather a vehicle for passing on particular philosophies, ideals and thoughts from one generation to the next (Petersen, 1995). This preference for literary and artistic elements clearly emerges in Fu, Lehto and Cai's (2012) review of travel advisory websites which revealed that Chinese tourists particularly liked sites that were linked to legends or stories of important historical characters. Similarly, Li (2008) notes that poets tend to be more revered than other historic figures - their homes are often restored as tourist attractions whereas residences of notorieties such as military generals rarely receive such attention.

There are also differences in the way Chinese and Western cultures view built heritage sites. Unlike Europe with its cathedrals, palaces and classical Grecian and Roman ruins, in China there are few examples of original ancient monuments and buildings. European tradition was to build monuments and buildings in materials that were strong enough to withstand the ravages of time whereas the Chinese approach was to use perishable and fragile materials that required frequent rebuilding (Ryckmans, 2008). In China, buildings can be built and rebuilt many times during their lifetime (a concept that exists in other Asian countries too, for a variety of reasons). Eternity for the Chinese is assured through the spiritual meaning and design of the heritage site not the physical nature of the site itself. Poetry, art and essays inspired by the site all help to preserve it for posterity. Continuity is therefore assured through successive generations of humans passing on the ideas and written work inspired by heritage sites - the physical building or object is almost of secondary importance (Ryckmans, 2008). While it is tempting to deduce from the above that authenticity is not important for Chinese visitors, this is not the case. Authenticity is very important, but resides in the fusion of the physical building, its spiritual meaning and the site itself. A structure can be built and rebuilt many times yet still retain its authenticity: it is the place, and the literary works it has inspired, that makes it 'authentic' (Xu, Ding and Packer, 2008).

Another way in which the Chinese worldview differs from the West is that it is anthropocentric (placing humans first) and anthropomorphic (animals, plants and natural features are given human characteristics). The Chinese view natural and cultural heritage as one entity; thus, they willingly accept the construction of man-made structures in natural environments (Sofield and Li, 2007). In China it is considered good management to create tourism facilities such as gardens, artificial lakes and waterfalls, roads, concrete paths and observation lookouts that 'improve' natural heritage sites. Indeed, researchers claim that most Chinese tourists expect 'scenic spots' to have been developed or improved and that there is a strong desire for modern structures at these sites (Sofield and Li, 2007 \& 2011). This approach to modernising or enhancing natural and heritage landscapes contradicts common international 'Western' conventions of 'best practice' heritage management where commodification is carefully concealed and designed not to impinge upon site authenticity (Nyiri, 2009). 'Western' views of nature and tourism support and emphasise the maintenance of ecosystems, even if this prevents humans accessing these areas for recreational or tourism purposes (Sofield and $\mathrm{Li}, 2007$ ). In China, tourism resources are neither solely natural resources nor solely cultural resources but a fusion of the two (Wen and Ximing, 2008). Heritage buildings such as temples and pavilions are often constructed in places of great 
natural beauty, further cementing the union between cultural and natural landscapes. According to Wen and Ximing (2008), the Chinese preference for culture means that tourists are "...willing to accept those tourism activities more or less combining nature and culture" (p.579). Because of this, it is argued that findings from natural settings are likely to provide useful insights into visitors' preferences and perceptions at cultural sites.

As argued earlier, visitors' interpretive experiences are defined not only by what exists at a site but also by what visitors bring with them - their thoughts, motives, beliefs and preferences - which are greatly influenced by their cultural background. In many cases it is one's culture that defines the demarcation line between modern and traditional, authentic and inauthentic, 'good' or 'poor' taste (Winter, 2009). For the Chinese, the fusion of history, psychology, botany and literature is seen as totally appropriate and desirable in relation to heritage interpretation ( $\mathrm{Li}$ and Sofield, 2009). In the Chinese worldview, literature and art are as important as the sciences, thus visitors to areas of natural beauty will 'make sense' of their experiences by referring to the human values attributed to features of the site in famous literary or artistic pieces. Many international visitors from a Western cultural background are unaware of a Chinese landscape's cultural significance in inspiring great literary works and art. Accordingly, Chinese and international visitors are likely to have different interpretive needs - differing cultural 'spectacles' will colour their appreciation, preferences and perceptions of heritage sites in China.

It is evident that differences in cultural perspectives between visitor worldviews pose a substantial challenge for interpreters - how, for example, can Chinese natural and built heritage environments be interpreted in a way that appeals to both Chinese and international visitors? Is it possible to 'kill two birds with one stone', or should we be developing different interpretive products and services for each 'cultural' market? Hongying and Hui (2009) give some insights into this problem when they note that many Chinese tour guides have difficulty meeting the growing demands from international visitors for relevant, insightful information on China's history and culture. After observing more than twenty guided tours in major Chinese cities, they identified several key features of Chinese interpretive practice:

- commentaries focus on important historic events and past experiences - there is little coverage of contemporary everyday life (e.g., daily routine, family life, customs and traditions);

- interpreters focus on cultural aspects of the landscape - geographical features, flora and fauna receive little mention;

- stories focus on famous people - guides rarely talk about their own experiences or experiences of local residents;

- lakes, mountains and other features of the landscape are interpreted by referring to their place in legends or fairy tales - scientific perspectives are seldom used as it is believed that tourists participate in tours for fun not education per se; and

- explanations about Chinese society tend to be superficial, preventing international visitors obtaining insights into the host community (Hongying and Hui, 2009). 
Io's (2013) observation of Chinese tour guides in Macau revealed similar issues, with guides rarely telling personal stories or giving local, more personal perspectives on the history of the city and its inhabitants.

Recently, Wong (2013) interviewed fourteen guides offering tours for independent tourists at Macau's heritage sites to explore what topics and issues were included in their commentaries. Responses indicated that the guides adjust their commentaries depending on the cultural backgrounds of their group. Tourists from Western countries, Singapore and Malaysia are told about the colonial history of Macau and maritime trade, whereas Chinese tourists are not given this information because guides have found they are more interested in sights, displays and vantage points for taking photographs. Guides also reported that Chinese tourists were interested in more light-hearted information such as stories and folklore, particularly in relation to winning money in casinos.

$\mathrm{Xu}$ et al (2013) make similar observations about interpretation in natural heritage sites, noting that Chinese guides use an aesthetic approach - stories, art and poetry - that are highly appreciated by Chinese visitors. While these interpretive practices would appear to meet the needs of Chinese visitors, they do not reflect expected international practice that is 'grounded' in Western culture and accordingly may not appeal to international visitors. To further complicate matters, many Chinese heritage sites either have, or are aiming to attain, World Heritage Site status. One of the nomination requirements for accreditation is that the site provides visitors with interpretation in the form of signage, trails, publications, guides, interpretive centres and/or museums/exhibitions (UNESCO, 2012). In Chinese national parks and protected areas, this interpretation typically takes the form of information that explains the scientific processes responsible for creating the physical landscape. However, research by Xu et al (2013) in Danxia Shan National Natural Reserve and Geo Park indicates that such approaches are not well regarded by Chinese visitors.

From personal experience it appears that designers of on-site heritage interpretation experiences in China have made little if any effort to consider possible cultural differences between Chinese and international visitor perceptions of, and preferences for interpretation. How do Chinese visitors view interpretation provided at tourist heritage sites in China compared with international visitors? How satisfied are Chinese with the interpretation they receive at their heritage sites? Undertaking empirical research to answer such questions is important as the principles and practices of interpretation at Chinese heritage sites are largely informed by Western (European) values, ideals and best practice that may not meet Chinese visitor needs and preferences (Sofield and Li, 1998; Staiff, Bushell and Kennedy, 2002; Xu et al., 2013).

From above, there is clearly a need to examine whether (and how) visitors' cultural background impacts on their interpretive needs and experiences at Chinese heritage sites and to use such understanding to design culturally appropriate and effective interpretation for both Chinese and international visitors. Moscardo (2007) calls for more research exploring the extent to which principles of interpretation can be universally applied, particularly in relation to whether different cultural groups have different preference for the style and extent 
of interpretation. Accordingly, this study aims to identify cultural differences and similarities between Chinese and international visitors in relation to their motives, preferences and perceptions relating to interpretation provided at five key built heritage sites in Beijing.

\section{Method}

\section{Instrument}

The questionnaire used in this research was designed to identify similarities and differences between Chinese and international visitors' motives for visitation; conceptions of heritage; and preferences for and perceptions of interpretive services, facilities and topics of information. Motives were measured using Falk and Storksdieck's (2010) five broad identity categories of Explorers (visitors who are curiosity-driven with a generic interest in the site), Facilitators (those who are socially motivated and there to facilitate the experience and learning of others); Professional/Hobbyists (those who have an interest or passion in the site/topic); Experience Seekers (those who are motivated to visit by the site's importance); and Rechargers (those who seek a contemplative, spiritual or restorative experience). These identity-related motives have been used to explore and analyse visitors' experiences and reactions to interpretation in a number of free-choice learning environments such as museums (Falk and Storksdieck, 2010), wildlife sites (Ballantyne, Packer and Falk, 2011) and heritage sites (Hughes, Bond and Ballantyne, 2013). Scales measuring preferences for, and perceptions of, interpretive services and facilities were based on 'best practice' principles of interpretation (Ham, 1992; Moscardo et el., 2007; Munro et al., 2008). Where appropriate, items were also adapted from Hughes et al.'s (2013) study of visitors' interpretive needs at Canterbury Cathedral, a heritage site in the UK. Items in the question exploring visitors' conceptions of heritage were taken from Western definitions of heritage tourism (Timothy and Boyd, 2003), as well as descriptions of key characteristics of Chinese cultural ecotourism sites (Ryckmans, 2008; Xu et el., 2008; Wen and Ximing, 2008).

The questionnaire in English was pilot-tested with two academics and two students who had been to the five Beijing tourist sites. Feedback prompted minor alterations prior to one of the authors translating the survey items into Mandarin. The Mandarin version was then pilottested and back-translated by two Chinese staff at the University of Queensland to ensure the accuracy of the translation. A copy of the English version of the questionnaire can be found as an appendix to the online version of this paper.

\section{Procedure}

International and domestic visitors were sampled across five major tourist attractions in the Beijing region - The Great Wall of China (listed as a World Heritage Site (WHS) in 1987); the Forbidden City (WHS listed in 1987); The Summer Palace (WHS listed in 1998); the Temple of Heaven (WHS listed in 1998); and Beihai Park. These sites feature prominently in materials advertising the Beijing region and are widely considered 'must see' attractions. 
Data were collected by multi-lingual post-graduate students from the Beijing International Studies University (BISU) under the direction of one of the project team members, Professor Liu. This was conducted in May/June to coincide with peak tourist season in China (spring/summer) and therefore maximise opportunities to sample both international and domestic tourists. Researchers were stationed at the main entrances to the five tourist sites. Visitors were randomly approached and asked to participate in a study exploring the interpretive needs and perceptions of people visiting key tourist sites across the Beijing region. Those who agreed to be involved were given a questionnaire and a pen, and asked to complete the questions referring to motives and preferences at the entrance (pre-visit) and the remainder of the questionnaire upon exiting (post-visit). Visitors were not approached if they were part of a tour group as it was felt their preferences and perceptions of interpretation may have been coloured by the commentaries of the tour guide.

\section{Participants}

Three hundred and seventy-one respondents were sampled across the five heritage sites -277 domestic Chinese visitors and 94 international visitors. Although the numbers of international visitors are only a third of the domestic numbers, this is considered representative as the latest figures (chinatourismonline, 2013) indicate there are substantially more domestic than international tourists visiting Beijing (140 million as opposed to 3.79 million). The majority of international visitors in the current study were from mainland Europe $(36 \%)$, USA $(23 \%)$ and the UK (15\%). Almost half of the international sample (49\%) was under 30 year old, and a further $32 \%$ were between 30 and 50 years old. The gender was evenly spread, with 44 males and 43 females and most (64\%) were first time visitors to the site. Twenty-seven per cent of the 277 Chinese respondents were Beijing residents. As with Western visitors, the majority (69\%) were under 30 years old. A further $21 \%$ were aged between 30 and 49. Gender was also fairly even, with 120 males (45\% of the sample) and 146 females - 13 respondents did not answer this question. Just over half of the sample (54\%) had not been to the site before.

Chi-square tests revealed that there was a significant difference between international and Chinese visitors in terms of their motives for visiting $\left(\chi^{2}(4,300)=27.895, p<.000\right)$. Using Falk and Storksdieck's (2010) model, Chinese were predominantly visiting to bring a friend or family member (43\% of the sample); because they had an interest in China's cultural heritage (23\%); or to see a famous attraction (22\%). International visitors mainly came to see a famous attraction (43\%) and because of a particular interest in China's cultural heritage $(27 \%)$. Few of either visitor groups reported that they came to learn or discover something new or for restorative/relaxation reasons.

\section{Results}

This research was designed to explore differences between Chinese and international tourists' preferences for, and perceptions of, interpretation offered at five Beijing heritage sites.

Conceptions of heritage 
Respondents were asked to rate their perceptions of the importance of specific features of heritage sites on a scale of 1 (not at all important) to 7 (extremely important). Table 1 illustrates responses in order of importance according to Chinese respondents. For Chinese respondents, key important features of heritage sites are that they are part of the country's national heritage and character; are beautiful and famous; are well cared for and in good condition; and the buildings and structures are original/authentic. International visitors also felt that being part of the country's national heritage and character was an important characteristic of heritage sites, as was having original/authentic buildings and structures; being beautiful; and being well-cared for and in good condition. From Table 1 it is noted that Chinese respondents were significantly more likely than international respondents to state that heritage sites needed to be an important part of the country's national heritage and character, convey the country's power, and be famous. They were also more likely to state that heritage sites should be educational, be visited by someone famous, and feature in wellknown paintings and poetry; however, the effect size for the latter three is small. International visitors were significantly more likely than Chinese to state that heritage sites needed to have buildings and structures that were old.

[Insert Table 1 about here]

\section{Facilities and Services}

Secondly, respondents were asked to indicate the importance of facilities and services commonly found at heritage sites on a five point scale from 1 (not at all important) to 5 (essential). They were then asked to rate how well the site performed on these items on a scale of 1 (very poorly) to 5 (very well). Chinese visitors rated the following services and facilities as the most important: information panels; directional signs; perceived value for money; seating and friendly/helpful staff. Western visitors felt information panels were the most important followed by friendly/helpful staff and directional signs. Differences between Chinese and international visitor responses to their perceptions of the importance of heritage site facilities and services are graphically illustrated in Figure 1.

[Insert Figure 1 about here]

While the pattern of responses is somewhat similar for the two groups, t-tests indicate significant differences between the visitor groups on the perceived importance of eight of the thirteen services and facilities measured. Chinese visitors placed significantly more importance on guided tours, value for money, information panels/signs, seating, audio tours, directional signage, and educational materials to take home. Western visitors placed significantly more importance than Chinese on displays and exhibits (See Table 2). These differences were largest for directional signage, value for money, audio tours and displays and exhibits.

[Insert Table 2 about here] 
To explore visitors' preferences for interpretive content, respondents were asked to rate the importance of providing interpretation on particular topics. Chinese respondents regarded the following topics/emphases as most important: information that provides an insight into Chinese culture; information about how the site was built; legends and traditional stories relating to the site; and facts and figures about the buildings/structures. Most important to international respondents was a focus on information providing an insight into Chinese culture, how the site was built and the people who lived there. However, unlike Chinese visitors, international visitors felt that an explanation of why the site was significant was equally important. Differences between Chinese and Western preferences for interpretation are illustrated graphically in Figure 2.

[Insert Figure 2 about here]

T-tests reveal that these differences are significant for nine of the eleven topics listed. Chinese visitors were significantly more likely than international visitors to want interpretation to cover how the site was built, events that happened, facts and figures about the buildings, legends and traditional stories, Chinese culture, famous people who have visited the site, how the site is looked after, and poetry about the site and surroundings. Western visitors thought information about who once lived and worked at the site was significantly more important than Chinese visitors did (see Table 3). The effect size was greatest for information about who had lived or worked at the site, how the site was managed and the names of famous people who had been to the site.

[Insert Table 3 about here]

The views of Chinese and Westerners were similar with regards to how well the sites performed in relation to these topics, with the only significant difference being that international visitors rated presentation of 'information about who lived at the site' higher than Chinese did ( $\mathrm{t}[338]=3.005, \mathrm{p}=.003)$. Thus it seems that although preferences differed markedly between the two cultural groups, their perceptions about the quality of interpretation did not. It is possible that the similarity of perceptions is due to the age distribution of the sample. Most Chinese respondents (69\%) were under thirty and would, therefore, have been exposed in high school and tertiary studies, and via e-media, to Western principles and concepts about heritage and tourism. Had the sample contained a greater proportion of older respondents, perceptions may have reflected more traditionalist views and produced more pronounced differences. However, data collectors were asked to obtain a representative sample of site visitors - researchers reported that the majority of independent visitors to the sites selected were in fact younger. Thus, the results obtained are likely to reflect the views of visitors to the site.

It should be noted that Chinese visitors rated almost everything higher than international visitors, and that this pattern is consistent across the three tables presented in this section. Because items in the present study are based on Western research, it is possible that the results obtained in the present study reflect the way in which cultural groups respond to rating 
scales rather than differences in the perceived importance and performance of particular items per se. Whether this is unique to this particular sample of Chinese visitors, or whether this indicates a difference in the way the two cultural groups respond to questionnaires cannot be ascertained from the present study; however, this would be an interesting line of enquiry to explore in future studies. Both Moscardo (2007) and Van Dijk and Weiler (2009) have called for further research in this area; to the authors' knowledge this has yet to be conducted.

\section{Discussion}

\section{Conceptions of heritage}

Chinese respondents' conceptions of heritage focus on spiritual meaning and poetic/artistic merit. For this cultural group, a site's role in inspiring great works of art, its aesthetic qualities, and its ability to attract famous people are all considered fundamental to being labelled 'heritage'. These findings support previous studies exploring the Chinese concept of heritage sites. For example, Li and Sofield (2009) claim that Chinese domestic tourism often involves paying homage to artists and poets by visiting the sites that inspired their works; while Petersen (1995) describes the Chinese heritage tourist experience as one built on a tradition of following long-established routes and travelling in the steps of the famous. Thus, Chinese respondents' views that heritage sites should be famous; feature in well-known paintings and poetry; and be visited by someone famous is not surprising. Anecdotal evidence also suggests that physical evidence of having been to these sites (e.g., photographs of the Chinese tourist in-situ) is important for showing friends and family that one has been somewhere famous. It seems that the key factor is the fame and notoriety of the site, rather than site itself. This has important implications for the design of marketing materials and campaigns as it suggests that attracting the Chinese tourist requires an emphasis on the meaning, relevance, and fame of the site as well as its natural and built features.

The prominence Chinese respondents placed on heritage sites conveying the country's power and character probably stems from the Chinese practice of converting scenic areas into places of national pride. Indeed, the Deputy Director of the Sichuan Tourism Bureau is quoted as saying that the construction of tourist scenic spots "....must both fully reflect modern civilisation and fully display the positive and advancing spiritual civilisation of the Chinese race" (p.163, Nyiri, 2009). It is therefore not surprising that Chinese respondents felt heritage sites should convey the country's power and character and instil a sense of national pride.

\section{Services and facilities}

When asked to rate the importance of various services and facilities at heritage sites, Chinese respondents placed significantly more importance than international visitors on directional signage, value for money, audio tours, seating, educational materials to take home, guided tours, and information panels/signs. Many of these have been reported in previous studies of Chinese tourists. For example, $\mathrm{Xu}$ et al. (2013) observed that Chinese visitors to Danxia Shan National Nature Reserve and Geo-park made extensive use of directional signage to 
avoid getting lost - the same may apply in the present study as most of the sites sampled were extensive with a complex spatial layout.

The importance Chinese tourists ascribed to tour guides and audio tours is likely to reflect the prominence of tour guides in China (Hongying and Hui, 2008) as well as the Chinese tradition of passing on knowledge through stories, legends and poems. It also mirrors findings from $\mathrm{Xu}$ et al.'s (2013) study in which guides reported that Chinese tourists preferred stories and poems to the scientific information presented on interpretive signs. This issue will be explored further when discussing respondents' preferences for different types of interpretation.

Considering the relative youthfulness of this sample, it is surprising that provision of seating was also considered important. Given the importance Chinese place on visiting sites featured in famous paintings or literary works, it is possible that this preference is not for physical rest as such but rather for spaces that allow visitors to contemplate and absorb the atmosphere and spiritual meaning of the site. If this is the case, seats should be strategically placed to allow visitors to view the site from similar vantage points as those depicted in famous paintings or literary works. Such positioning is likely to heighten the feeling of 'walking in the footsteps of someone famous', and should consequently enhance and enrich the heritage experience. The emphasis the Chinese placed on 'value for money' suggests that heritage sites need to offer exemplary interpretive services and facilities at competitive prices if they are to continue attracting first time domestic tourists and, more particularly, repeat visitors.

The only items ascribed significantly more importance by international visitors than Chinese were 'displays and exhibits', probably because these are common and expected elements of Western interpretation but rarely feature at Chinese sites.

\section{Interpretive Content}

Researchers have noted that many World Heritage sites in China have incorporated interpretation in order to attain WHA status, yet the quality of this interpretation rarely complies with 'best practice' principles as described in Western texts (Ham, 1992; Moscardo, et al., 2007; Tilden, 1977;). To illustrate, Xu et al. (2013) describe signage at Danxia Shan as being similar to old-fashioned labels found in botanical gardens; while Sofield and Li (2007) reveal that in many caves in China visitors are encouraged to imagine cave formations as particular animals or touch particular formations for luck. Messages relating to conservation, ecology and/or biological processes are notably absent (Sofield and $\mathrm{Li}, 2007$ ). If preferences and perceptions are built on previous experience, it is likely that Chinese visitors' responses will differ from those of international visitors. The results of this study would suggest that this is the case, with significant differences found between Chinese and international visitors' views on nine of the suggested eleven interpretive topics rated.

The Chinese preference for topics such how structures were constructed, important events connected to the site, and information about how the site is managed highlights their interest in learning about the improvements and enhancements humans have made to heritage landscapes. These preferences support claims that the Chinese anthropocentric worldview 
sees humans and the environment as interconnected and that man-made structures are considered to enhance tourism experiences (e.g. Sofield and Li, 2007; Winter, 2009).

Given China's centuries old tradition of honouring poetic and artistic talents (Petersen, 1995; Sofield and Li, 1998), the importance Chinese visitors placed on legends, stories, traditions and cultural information is also not surprising. In the Chinese worldview, literature and art are highly valued, therefore interpretation relating to famous literary or artistic pieces could be instrumental in assisting Chinese tourists to 'make meaning' of their heritage experiences. Visitors' preference for stories and legends was also mentioned by tour guides in Wong's (2013) study of guiding in Macau's historic sites. As domestic tourism is built on a tradition of 'following in the footsteps of the famous' (Li and Sofield, 2009), it also seems logical that Chinese visitors would want interpretation to include the names of famous people who have visited the site.

Together these findings suggest that for Chinese visitors, heritage interpretation should focus on how (and by whom) sites were constructed and are currently maintained; literary and artistic works that the site has inspired; and famous people the site has attracted. This supports Li and Sofield's (2008) assertion that being familiar with famous works of art and visiting the source of the artist's inspiration is an important part of the Chinese tourism experience. The finding that international visitors were more interested than Chinese in stories of everyday life matches one of the key tenets of Western interpretation - that interpretive content should be relevant and include aspects of everyday life (Ham, 1992; Moscardo et al., 2007). Thus, for international tourists, it is the everyday, the contemporary, the 'here and now' that plays a key role in furthering their understanding of heritage sites. Such is not likely to be of major interest to Chinese visitors which explains why interpretation in China rarely covers everyday life or contemporary issues (Hongying and Hui, 2009; Io, 2013).

\section{Conclusion: areas for further research}

Results obtained in this and previous studies of Chinese visitors at natural and heritage attractions suggest that although some of their views of interpretation are similar to those of international visitors, there are also some key differences. These relate to both the mode of delivery and the content and focus of interpretation. While further research is needed to ascertain whether the interpretive needs, preferences and perceptions of Chinese tourists apply in other contexts (both in China and other countries), it seems that for the Chinese, interpretive experiences should aim to 'tap into' the cultural ethos of revering artistic and literary works; 'reliving' moments of inspiration; knowing about important people who have visited the site; and generally appreciating the beauty and spiritual meaning of views and vistas.

Another area to investigate relates to the generalisability of this study's finding that interpretation of the everyday, the ordinary, and the scientific are unlikely to be as well received or appreciated by Chinese visitors to heritage sites as they are by international visitors. Such research will inform the design and delivery of interpretation and the creation 
of visitor experiences that are informative, engaging and memorable for both Chinese and international visitors. In this way, as Weiller and Kim (2011) suggest, interpretation will be able to contribute to the sustainability of heritage sites by enhancing visitors' understanding and appreciation of the sites being visited; encouraging their compliance with proconservation behaviour (e.g., not touching or walking on fragile resources); and providing experiences that engender satisfaction and positive word of mouth advertising.

The extent to which conceptions of heritage and authenticity are culturally defined is deserving of further study. While Chinese respondents in this study felt that heritage sites needed to have elements of authenticity to be considered 'heritage', their concept of authenticity did not appear to be linked to the age and 'original' condition of the structures. In fact, Chinese respondents rated age as the least important defining characteristic of 'heritage', reflecting the common Chinese practice of repairing, replacing and rebuilding ancient structures (Ryckmans, 2008). Perhaps, as Ryckmans (2008) and Xu et al. (2008) claim, authenticity refers to the spiritual meaning of the site which is embedded in the poems, stories and artworks it has inspired - the structure itself may even be incidental. This notion requires further exploration, together with research to tease out exactly how Chinese definitions and conceptions of heritage and authenticity differ from Western perspectives.

Although Chinese visitors expressed a preference for interpretive services and facilities at the five sites selected, this may be because four of them are World Heritage Sites - it may well be that expectations are not as high for lesser known sites. While inferences were drawn from and for interpretive practice at other heritage sites in both China and Western countries, it is possible that preferences and perceptions of both Chinese and Western visitors may not be constant in other tourism contexts. Further research at other heritage sites both in China and Western countries is needed to ascertain whether the differences highlighted in this and other studies are consistent and widespread.

Research is also needed to investigate whether key principles of interpretation in free-choice learning situations are 'cultural' in nature, reflecting mainly the perceptions of 'Western' visitors. Are there different principles based on other cultural views (such as those of the Chinese) to appreciating the natural and built environment that would be more appropriate for interpretation of Chinese heritage sites? This question mirrors those that have been considered and debated in relation to 'the Chinese learner' in formal Higher Education research generally (Watkins. and Biggs, 1996). Is there a 'cultural' difference in the way Western and Chinese visitors learn at, and 'make sense of', heritage sites? If so what are these and how should they affect the nature and design of interpretation experiences for Chinese visitors?

Finally, this study provides evidence that cultural differences in interpretation preferences exist in relation to mode of delivery, style and focus of interpretive experiences. Accordingly, perhaps for Chinese visitors, Ham's (1992) well-established EROT principles for interpretation (Entertaining, Relevant, Organised and Thematic), could be 'tweaked' to ERAT (Entertaining - stories and legends about people and landscapes; Relevant - to Chinese 
worldview; Aesthetic - focused on the beauty, spiritual meaning and 'atmosphere' of the site; and Traditional - based on cultural beliefs and practices)?

\section{References}

Austin, N.K. (2002). Managing heritage attractions; marketing challenges at sensitive historical sites. International Journal of Tourism Research, 4, 447-457.

Ballantyne, R. (1998) Interpreting 'visions': addressing environmental education goals through interpretation, In, Contemporary Issues in Heritage and Environmental Interpretation - Problems and Prospects, pp. 77-97London: The Stationery Office.

Ballantyne, R. (2003) Interpreting Apartheid: visitors' perceptions of the District Six Museum. Curator: The Museum Journal, 46 (3): 279-292.

Ballantyne, R., Packer, J. and Falk, J. (2011) Visitors' learning for environmental sustainability: testing short- and long-term impacts of wildlife tourism experiences using structural equation modelling. Tourism Management, 32(6), 1243-1252.

Ballantyne, R., Packer, J. and Sutherland, L. (2011) Visitors' memories of wildlife tourism: Implications for the design of powerful interpretive experiences. Tourism Management, 32, 770-779.

Bonn, M.A., Joseph-Mathews, S.M., Dai, M., Hayes, S. and Cave, J. (2007). Heritage/cultural attraction atmospherics: Creating the right environment for the heritage/cultural visitor. Journal of Travel Research, 45, 345-354.

Chinatoursonline Beijing tourism. Retrieved on 30 $0^{\text {th }}$ June 2013 from http://www.chinatouronline.com/china-travel/beijing/beijing-tourism/index.html

Cui, Q., Xu, H. and Wall, G. (2012) A cultural perspective on wildlife tourism in China. Tourism Recreation Research, 37(1), 27-36.

Falk, J., \& Storksdieck, M. (2010). Science learning in a leisure setting. Journal of research in science teaching, 47(2), 194-212.

Falk, J. H. \& Dierking, L. D. (2000). Learning from museums: Visitor experiences and the making of meaning. Walnut Creek, CA, Alta Mira Press.

Fu, X., Lehto, X.Y. and Cai, L.A. (2012). Culture-based interpretation of vacation consumption. Journal of China Tourism Research, 8, 320-333.

Ham, S.H. (1992). Environmental interpretation: A practical guide for people with big ideas and small budgets. Golden, Colorado, North American Press. 
Hongying, Y. and Hui, C. (2009). Analysis of tour guide interpretation in China. In C.Ryan and G.Huimin (Eds.) Tourism in China: Destination, cultures and communities, pp. 225 236, New York: Routledge.

Hughes, K., Bond, N. and Ballantyne, R. (2013). Designing and managing interpretive experiences at religious sites: Visitors' perceptions of Canterbury Cathedral, Tourism Management, 36 (1):210-220.

Io, M.-U. (2013). Testing a model of effective interpretation to boost the heritage tourism experience: A case study in Macao. Journal of Sustainable Tourism, 21(6), 900-914.

Li, F.M.S. and Sofield, T.T.H. (2006). World heritage listing: the case of Huangshan (Yellow Mountain), China. In Leask, A. and Fyall, A. Managing World Heritage Sites, pp. 250-262, Taylor and Francis: Hoboken.

Li, F.M.S. and Sofield, T.T.H. (2009). Huangshan (Yellow Mountain), China. In C.Ryan and G.Huimin (Eds.) Tourism in China: Destination, cultures and communities, pp. 158-167, New York: Routledge.

Moscardo, G., (1998). Interpretation and sustainable tourism: Functions, examples and principles. The Journal of Tourism Studies, 9(1), 2-13.

Moscardo, G. (2003). Interpretation: Communicating across cultures. In T.Griffin and R.Harris (Eds.) Current research, future strategies: Bridging uncertainty. Asia Pacific Tourism Association $9^{\text {th }}$ Annual Conference. July 6-9 ${ }^{\text {th }}$, University of Technology, Sydney.

Moscardo, G., Ballantyne, R., and Hughes, K. (2007). Designing interpretive signs: Principles in practice. Colorado, Fulcrum Press.

Munro, J.K., Morrison-Saunders, A. and Hughes, M. (2008). Environmental interpretation in natural areas. Journal of Ecotourism, 7(1), 1-14.

Nyiri, P. (2009). Between encouragement and control: Tourism, modernity and discipline in China. In T.Winter, P.Teo and T.C. Chang (Eds.) Asia on tour: Exploring the rise of Asian tourism, pp. 153-169, London: Routledge.

Petersen, Y.Y. (1995) The Chinese landscape as a tourist attraction: Image and reality. In A.A Lew and L.Yu (Eds.) Tourism in China: Geographic, political and economic perspectives, pp.141-154, Colorado: Westview Press.

Poria, Y., Butler, R. and Airey, D. (2003). The core of heritage tourism. Annals of Tourism Research, 30 (1), 238-254.

Poria, Y, Reichel, A. and Brian, A. (2005). Heritage site managements: Motivations and expectations. Annals of Tourism Research, 33(1), 162-178. 
Powell, R.B. and Ham, S. (2008). Can ecotourism interpretation really lead to proconservation knowledge, attitudes and behaviour? Evidence from the Galapagos Islands. Journal of Sustainable Tourism, 16(4), 467-489.

Ryckmans, P. (2008). The Chinese attitude towards the past. China Heritage Quarterly, 14, Retrieved on $4^{\text {th }}$ October 2012 from http://www.chinaheritagequarterly.org/articles.php?searchterm=014_chineseAttitude.inc\&iss $\underline{\text { ue }=014}$

Staiff, R., Bushell, R. and Kennedy, P. (2010) Interpretation in national parks: Some critical questions. Journal of Sustainable Tourism, 10(2), 97-113.

Sofield, T.H.B. and Li, F.M.S. (2007). China: Ecotourism and cultural tourism, harmony or dissonance? In J.Higham (Ed.) Critical issues in ecotourism: Understanding a complex tourism phenomenon, pp.368-385, Burlington: Taylor and Francis.

Sofield, T.H.B. and Li, F.M.S. (1998). Tourism development and cultural policies in China. Annals of Tourism Research, 25(2), 362-392.

Sofield, T.H.B. and Li, F.M.S. (2011). Tourism governance and sustainable national development in China : a macro-level synthesis Journal of Sustainable Tourism, 19 (4-5): 501-534.

Tilden, F. (1977). Interpreting our heritage. $3^{\text {rd }}$ ed. Chapel Hill: University of North Carolina Press.

Timothy, D.J. and Boyd, S.W. (2003). Heritage tourism. Harlow, UK, Pearson Education Limited.

UNESCO 2012 Operational Guidelines for the Implementation of the World Heritage Convention. Retrieved on 15th January, 2012 from http://whc.unesco.org/en/guidelines/

Ung, A. and Vong, T.Z. (2010) Tourist experience of heritage tourism in Macau SAR, China. Journal of Heritage Tourism, 5(2), 157-168.

Van Dijk, P.A., Smith, L.D.G. and Weiler, B. (2012). To re-enact or not to re-enact? Investigating the impacts of first- and third-person interpretation at a heritage tourism site. Visitor Studies, 15(1), 48-61.

Xu, H., Cui, Q., Ballantyne, R. and Packer, J., (2013) Effective environmental interpretation at Chinese natural attractions: the need for an aesthetic approach, Journal of Sustainable Tourism, 21(1): 117-133.

Xu, H., Ding, P. and Packer, J. (2008) Tourism research in China: Understanding the unique cultural contexts and complexities. Current Issues in Tourism, 11(6), 473-491. 
Wah, C.Y. (2009). Disorganised tourism space: Chinese tourists in an age of Asian tourism. In T.Winter, P.Teo and T.C. Chang (Eds.) Asia on tour: Exploring the rise of Asian tourism, pp.67-77, New York: Routledge.

Watkins, D. and Biggs, J., (1996) The Chinese Learner: Cultural, Psychological and Contextual Influences. Melbourne, The Australian Council for Educational Research, Ltd.

Weiler, B. and Kim, A.K. (2011). Tour guides as agents for sustainability: Rhetoric, reality and implications for research. Tourism Recreation Research, 36(2), 113-125.

Weiler, B. and Yu, X. (2007). Dimensions of cultural mediation in guiding Chinese tour groups: Implications for interpretation. Tourism Recreation Research, 32(3), 13-22.

Winter, T. (2009). The modernities of heritage and tourism: Interpretation of an Asian future. Journal of Heritage Tourism, 4(2), 105-115.

Wong, C.U.I. (2013) The sanitization of colonial history: authenticity, heritage interpretation and the case of Macau's tour guides Journal of Sustainable Tourism, 21(6): 915-931. 